\title{
Study on the Physical Education Curriculum Model of China's Newly-upgraded Universities
}

\author{
Haiting Li \\ Department of Physical Education, Henan University of Animal Husbandry and Economy \\ Zhengzhou, Henan 450046
}

\begin{abstract}
With the development of higher education in China, the local education departments have carried out macrointegration of the universities under their jurisdiction. Some old or strong junior colleges have been upgraded to undergraduate universities, but the problems in physical education curriculum model of these universities after the upgrading are increasingly exposed. Therefore, the physical education reform in newlyupgraded universities is imminent. In this paper, the author makes an in-depth study on the current situation and influencing factors of the physical education curriculum model of newlyupgraded universities in China by using various scientific research methods. Finally, the author puts forward some constructive countermeasures from curriculum setting, the content, the arrangement of time and space, teaching methods, achievement evaluation and other aspects, aiming at providing some theoretical references for the healthy and orderly development of the physical education curriculum model of newly-upgraded universities in China, and making some contribution to the physical education cause of China.
\end{abstract}

Keywords-Newly-upgraded universities; Colleges and universities; Physical education curriculum; Model

\section{INTRODUCTION}

With the progress of our society and the development of economy, the society has a higher demand for talents. Colleges and universities bear the important task of cultivating comprehensive professional talents for our country, and the physical education of colleges and universities should be adapted to this. Physical education teaching is the most important part of school physical education, and it is the main process to realize school physical education task. Improving the level and quality of physical education teaching has become the primary task of school physical education. As we all know, under the guidance of "health first, lifelong sports", strengthening health and educating people have become the teaching goal of physical education in colleges and universities. "How to establish a physical education curriculum model suitable for the guiding ideology and teaching objectives" has become a problem worthy of further discussion. So, strengthening the study of physical education curriculum model in China's colleges and universities is very important to deepening the reform of physical education in colleges and universities in our country, implementing the all-round implementation of quality education and lifelong physical education, and training high quality professionals for our country. With the development of higher education in our country, the education department has carried on a series of macro-integration of universities, and some junior colleges have been gradually upgraded to undergraduate universities. The existing problems of physical education in these newlyupgraded universities have gradually become obvious. Therefore, the reform of physical education in these newlyupgraded universities is imperative.

\section{RESEARCH OBJECTS AND RESEARCH METHODS}

\section{A. Research Objects}

The author has randomly selected 50 newly-upgraded universities across the country and taken the public physical education curriculum model of these universities as the research object, mainly involving curriculum objectives and setting, teaching content, teaching methods, evaluation of physical education achievement and so on.

\section{B. Research Methods}

In the course of the study, the author mainly adopted a variety of scientific research methods of physical education, such as literature review method, interview method, questionnaire method, mathematical statistics method, logical analysis method and so on.

\section{RESULTS AND ANALYSIS}

Status Quo of Physical Education Curriculum Model in Newly-upgraded Universities in China

In the survey, it is found that the public physical education curriculum models of newly-upgraded universities in China are mainly divided into two types: single type and compound type. The former mainly includes the primary and secondary combination curriculum model, semi-traditional model and semi-open model. The latter refers to the combination of two or more curriculum models.

\section{A. Cognition of Physical Education Curriculum Objectives in Newly-upgraded Universities in China}

According to the level division of curriculum objectives, it can be divided into: overall curriculum objectives, subject curriculum objectives and curriculum objectives [1]. The physical education curriculum objectives of universities in China rank the third level, and the objectives of this level can play the most direct and specific role in curriculum design. 
Whether the overall curriculum objectives and the subject curriculum objectives can be achieved depends on whether we can decompose the objectives scientifically and effectively, and the objectives can be realized in concrete practice teaching.

It is found that nearly half of the PE teachers in newlyupgraded universities in China tend to confuse the objectives of school physical education with those of physical education teaching. Therefore, in the actual work of constructing teaching objectives, it is necessary to improve the relationship between teaching and learning, increase the degree of attention to the students' main body needs, and improve the transformation mechanism of teaching and learning objectives. At present, no matter universities, middle schools or primary schools, the physical education objectives involve morality, intelligence, physique and aesthetics. Therefore, how to organize teaching activities when PE teachers encounter problems in achieving these objectives and how to achieve these objectives are urgent problems to be solved.

\section{B. Teaching Materials and Physical Education Models Used}

According to the survey, some of the newly-upgraded universities adopted unified textbooks, while others adopted self-designed textbooks. However, the contents of the teaching materials that involve technical teaching are still derived from the competitive sports model, and the theoretical part is mostly the purpose, task, principle and significance of physical education. These textbooks lack entertainment and practicality, and it is difficult to stimulate students' interest and enthusiasm in learning.

\section{Basic Situation of Physical Education Teaching}

According to the survey, the physical education courses in the newly-upgraded universities are mainly for the freshmen and the sophomores. Only 1/10 of the colleges and universities set up physical education courses for the junior and senior students, one class each week, totaling 2 hours. $80 \%$ of the universities adopt their own syllabuses. Therefore, this shows that most college students have only two years of physical education, which obviously does not meet the requirements of the important goal of "cultivating college students of lifelong physical education" advocated by our college physical education. As we all know, sports habits cannot be developed through the physical education of only a few terms. It is continuous and needs to be driven by sports environment. Many people are not very fond of taking part in physical exercise at first, but they are gradually willing to follow in the sports environment, and develop interest in learning and sports, and then constantly improve their sports level. With the longterm persistence, the habit of lifelong physical exercise is gradually formed.

\section{Development and Implementation of Syllabus}

According to the survey, under the guidance of the national college physical education curriculum teaching guidance outline, the newly-upgraded universities can combine the actual situation of the school, and then demonstrate it, and design the suitable teaching syllabus and plan. In the survey, it is found that in the newly-upgraded universities, no matter the preparation of physical education teaching syllabus and teaching progress or the teachers' preparation of lessons, $80 \%$ of the PE teachers prepared fully, but a few PE teachers did not prepare lessons before class; only $62 \%$ of the teachers did well in teaching plan preparation; some teachers give lessons at will and do not follow the teaching plan, only $65 \%$ of the teachers give lessons in accordance with the teaching plan. Teaching facilities, teachers' concept, sports funds and so on will have an impact on the implementation of the syllabus. In the communication with front-line teachers, the author learned that most teachers fail to teach according to the teaching plan because of the influence of the teaching environment (including weather, venue, equipment, etc.). A few teachers think that this is also related to the school's assessment system, treatment and the teachers' professional quality. It can be seen that the relevant departments of the school should establish the supervision and restriction mechanism, improve the treatment of teachers, and intensify the training of PE teachers. At the same time, PE teachers must change their concepts, improve their professionalism and fully realize the importance of physical education.

\section{E. Contents and Methods of Physical Education}

In the survey, it is found that the sports in our newlyupgraded universities are mainly basketball, volleyball, football, aerobics, martial arts, table tennis, etc., tennis and badminton are getting more and more attention, and some new projects are gradually carried out in some colleges and universities, such as taekwondo, rock climbing and so on, while traditional track and field events are gradually fading. Most colleges and universities put quality practice into physical education classes in order to complete the Ministry of Education's physical fitness test. The survey shows that $50 \%$ of the teachers in our newly-upgraded universities have all the contents of the school syllabus, $35 \%$ of the teachers use part of the unified syllabus or the school syllabus. Only $15 \%$ of the teachers can fully adopt the unified syllabus. In terms of the frequency of use of teaching methods, the order is: practice method (90\%), demonstration method (91\%), teaching method (86\%) and teaching competition method $(65 \%)$. Collaborative teaching method and cooperative learning method only rank in the last two places. It can be seen that the teachers in the newlyupgraded universities are still based on the traditional teaching methods, the teaching methods are relatively backward, lack of innovative consciousness, the teaching effect is not ideal, and the syllabus is not fully implemented.

\section{F. Evaluation Criteria and Assessment of Physical Education Achievements}

The survey shows that there are some differences in the evaluation standards of physical education achievement in China's newly-upgraded universities, which are mainly based on three aspects: technical examination results, attendance and classroom learning performance, and physical fitness test scores. In terms of theoretical knowledge and after-school exercise, a few universities put these into the standards of physical education achievement evaluation, but the proportion of the two is very small. Most universities do not include theoretical courses in the achievement evaluation criteria. In addition, summative assessment is the main way to evaluate physical education achievement and process evaluation is less. 
This has greatly discouraged the students from attending class, and the way of physical education achievement assessment will play a great guiding role in physical education. Therefore, we should combine the process assessment and the result assessment organically, which is more scientific and reasonable, and is extremely beneficial to the students' ability in physical education and the cultivation of lifelong physical education consciousness.

\section{FACTORS AFFECTING THE PHYSICAL EDUCATION CURRICULUM MODEL IN NEWLY-UPGRADED UNIVERSITIES IN CHINA}

\section{A. The Basic Guiding Ideology of Physical Education Curriculum is not Clear Enough, and is Influenced by Traditional Ideas.}

Influenced by the educational system of the former Soviet Union, the physical education teaching of colleges and universities in our country emphasizes too much on mechanical imitation, standardizes and constrains students with classroom discipline and collective behavior, and neglects students' main body status [2]. Although this kind of old education thought and method once produced certain positive influence, it also hindered the students' personality development to a certain extent. It not only affects the improvement of college students' physical quality, but also restricts the full play of the efficiency of physical education in colleges and universities. It either regards physical education in colleges and universities as competitive sports, or looks at the task of physical education in colleges and universities from the perspective of biology, and does not regard it as an important subject. These conditions are very prominent in newly-upgraded universities. The main reasons are that these universities often refer to the physical education curriculum model of old undergraduate universities. Combining their own actual practice and the influence of traditional ideas, there are certain biases or deviations in the process of execution. At the same time, there is no good interaction and circulation in all links such as decision-making, management, execution and participation.

\section{B. There is Obvious Deviation between Teachers' Concept in Physical Education, Curriculum and Teaching and the Requirements of Physical Education Curriculum Reform}

The realization of physical education teaching objectives and the implementation of teaching reform in the newlyupgraded universities need the active cooperation and participation of teachers and students, but it is teachers who play a key role. At present, there are many problems in the concept of the newly-upgraded universities in our country: (1) The relationship between physical education and real life is not recognized clearly. (2) The students' dominant position and individual differences among students are not ignored, and less attention is paid to students' emotional experience in class [3]. (3) Curriculum inertia is serious, and curriculum consciousness is seriously lost. Nowadays, the social and economic development is swift and violent, and the times are changing constantly. This requires that physical education teaching in colleges and universities must make new adjustments and changes. It not only causes a certain impact on the traditional physical education concept, curriculum concept and teaching concept, but also puts forward more rigorous challenge to the teachers. Therefore, the PE teachers of newly-upgraded universities should change the original physical education concept, curriculum concept and teaching concept based on the reality, reposition their roles and constantly improve their comprehensive quality, so as to adapt to the requirements of higher education in the new era and the development of colleges and universities themselves. Only by renewing teachers' ideas and changing their roles can we build a new image of teachers, realize the objectives of physical education in colleges and universities, and further implement the reform of physical education teaching in colleges and universities.

\section{The Qualifications, Teaching and Scientific Research Abilities of PE Teachers cannot Meet the Requirements of Curriculum Reform}

The educational background of PE teachers marks the education level of teachers, the basic theoretical knowledge level and scientific research ability of teachers, and it indicates the potential ability of teachers in teaching, training and scientific research to a certain extent. The higher the educational background of teachers in a university, the higher the starting point, the greater the potential for development, and the higher the level of physical education, training and scientific research of the university. In addition, the title structure is also an important standard to measure the overall quality of a school's teacher team. It can reflect the level of teaching, training and scientific research of a school's teachers. In terms of educational background and professional title structure, the number of $\mathrm{PE}$ teachers in newly-upgraded universities with high professional title and high educational background is relatively low. This phenomenon causes some newly-upgraded universities powerless in physical education curriculum reform, and they can only imitate the curriculum model of some old underground universities or other newlyupgraded peer universities. The applied curriculum model is often disjointed with the actual situation of the school, and cannot really meet the requirements of physical education curriculum reform. This requires the newly-upgraded universities to continuously improve their educational background and gradually optimize their title structure.

\section{The Lack of Physical Education Teaching Equipment and Venue Facilities Restricts the Reasonable Setting of Physical Education Courses}

The sports equipment and venue facilities of the newlyupgraded colleges and universities in China are relatively deficient. In 2004, the General Office of the Ministry of Education issued the notice of the Catalogue of Facilities and Equipment for Sports Venues in Colleges and Universities, which made a clear regulation of the quota standards for various sports venue facilities. In the survey, it is found that the per capita possession of physical resources such as sports venue facilities in the newly-upgraded universities is far from the national standard, especially in some indoor venues, not to mention the venues of new sports items. In the final analysis, these problems are attributed to the lack of financial resources in these newly-upgraded colleges, and the sports leaders have 
to abandon something during curriculum setting. The students' favorite items can only limit the number and time because of the restrictions of the venues and equipment, which makes it difficult to implement the spirit of the New Program. Because of the shortage of venues, students often compete for venues, which can easily lead to student fighting. In addition, girls themselves do not like sports, the lack of equipment will make them far away from physical exercise, which is not only adverse to the smooth development of the school's physical education curriculum reform, but also affects the healthy and sustainable development of the school.

\section{E. Physical Education Curriculum Neglects the Regional Characteristics of Physical Education}

China is a country composed of 56 ethnic groups, with a vast territory and great differences in the level of economic development, natural conditions, national culture and sports hobbies. So, these newly-upgraded universities must combine the regional characteristics of physical education in physical education curriculum setting. At present, the newly-upgraded universities are blind in curriculum setting, and have not taken full consideration of regional characteristics, school characteristics and students' needs, and blindly follow the trend. They believe that opening as many types of courses or projects as possible can reflect the guiding ideology of "health first" and "education quality". As a result, the curriculum setting orientation are not clear enough, and the effect and objectives of curriculum teaching are not clear enough. Therefore, in the future curriculum reform, we must resolutely avoid these situations.

\section{F. The lag of Teaching Material Reform Hinders the Reform of Curriculum Model}

As one of the basic elements of teaching, teaching material is not only an important knowledge carrier of teaching thought, content and method, but also an important guarantee for deepening the reform of education and teaching and promoting quality education in an all-round way. Teaching material serves the goal of talent training in colleges and universities, and it will affect the quality of talent training to a certain extent [4]. The survey shows that the problems of physical education teaching materials in China's newly-upgraded universities are: lack of content innovation degree, relatively backward subject concept, lack of practicality and novelty. All of these seriously hinder the reform of curriculum model. Therefore, in the future reform, we need to strengthen the innovation of teaching materials.

\section{G. The Lag of Teaching Organization forms and Methods cannot Meet the Needs of Students.}

The purpose of teaching materials is achieved through a variety of teaching methods. A kind of teaching material may have many teaching methods at the same time [5]. On the choice of teaching methods, we should combine the main body of teaching to choose and apply flexibly, and adopt the most practical and effective teaching method. In order to better adapt to the curriculum reform, $\mathrm{PE}$ teachers should accurately grasp several principles: (1) The use of teaching methods must be able to give full play to the main role of students. (2) The application of teaching can not only enhance students' physique, but also cultivate their sense of sports. (3) The use of teaching method should focus on the cultivation of students' interests. In the survey, it is found that the organization form of PE teachers in newly-promoted universities in China is relatively rigid, and the teaching methods are single and backward, which is difficult to meet the needs of college students, causing the students' enthusiasm and interest in sports learning to decline, which is extremely unfavorable to the cultivation of students' interest in sports and the cultivation of sports consciousness.

\section{COUNTERMEASURES}

Make the curriculum setting scientific, step out of the competitive and procedural of sports curriculum, step out of the school gate, and integrate extracurricular physical exercise, offcampus activities and sports training into the curriculum system, and form the organically combined course structure inside and outside of the class and inside and outside of the school. Offer multiple types of physical education courses to all students in the school, break the recombination of departments and classes, and do the best to meet the needs of students of different grades, levels and interests.

Vigorously advocate open and inquiry teaching mode and expand the time and space of physical education curriculum. Use the form of questionnaire survey to understand the needs of students. Let students choose their own learning projects, teachers and class time, rearrange the class in combination with the actual situation of the school and the characteristics of the project and arrange the class hours. Include the sports training of students with special sports skills in sports courses, and offer special courses in rehabilitation and health care for special students with abnormal body and disability.

Transit the course content to modernization and life. Gradually improve school venues and facilities, and create more sports for students to choose. Students and teachers are combined with each other to learn and teach some sports knowledge and fitness methods with modern fitness flavor, and cultivate one or two sports skills or hobbies, and lay the foundation for the formation of lifelong physical education consciousness. The selection of teaching content should accord with their physical and mental development and pay attention to the scientific and practical nature of teaching content, and the most important thing is to combine students' interest in sports.

Adopt diversified teaching methods. The key to the reform of physical education in colleges and universities lies in how to enhance students' sense of participation and initiative in physical education, so as to make physical education an indispensable part of their lives. The sports participation of college students must be built on the basis of selfconsciousness and initiative. The classroom should be in the form of service-oriented health teaching with students as the main body and teachers as the leading, giving full play to the students' subjective initiative, paying attention to the individual differences, and promoting the multilateral mutual assistance between teachers and students and among students. Teachers should attach importance to the study of teaching methods, strengthen the guidance of learning methods and training 
methods for college students, and improve their ability of mutual assistance and self-training.

The credit setting should be flexible and humanized. There are a total of 4 credits in the physical education course, which should be completed in the 4 semesters of the first year and the second year. I $\mathrm{f}$ there is a restudy, you need to restudy before you can take other courses, and students are allowed to select in the third and fourth year.

In the sports achievement evaluation, we should discard the original skill evaluation and adopt integrity evaluation. The achievement evaluation structure is composed of learning attitude, special achievement and physical quality, and each part has quantitative or qualitative standards, and the sports achievement is calculated according to these standards. Practice teaching focuses on the evaluation of the process and students' sports ability, which can be evaluated jointly by teachers and students. Theoretical evaluation mainly examines the comprehensive level of students' knowledge of sports and health, which can be tested in the form of test papers or papers.

\section{CONCLUSION}

Multiple physical education curriculum models coexist in newly-upgraded universities, but most of them only refer to the curriculum models of other colleges and universities and make some attempts in combination their own practice. In addition to the influence of traditional ideas, there are certain biases or deviations in the process of implementation, at the same time, decision-making, management, implementation, participation and other links have not formed good interaction and circulation.

In terms of education background and professional title structure of PE teachers in newly-upgraded universities in China, the proportion of those with high professional title and high education background is relatively low. There is obvious deviation between the teachers' concept in physical education, curriculum, teaching and other aspects and the requirements of physical education curriculum reform. Teachers tend to ignore students' subjective status and individual differences, and seldom pay much attention to students' emotional experience in class.

There is a lack of physical education equipment, venues and facilities, inadequate investment in sports funds. Attention is paid to competition training, while the students' mass sports is despised. The allocation of venues, equipment and facilities for male and female students is not reasonable, and the venue and equipment suitable for female students are not as good as the resource allocation of male students.

The regional differences of sports are large, but some newly-upgraded universities blindly follow the trend, and some universities have lag phenomenon in physical education teaching material reform and need to be strengthened.

\section{ACKNOWLEDGMENT}

About the author: Haiting Li (1976-), male, Han nationality, Nanyang, Henan, master, associate professor, research direction: physical education teaching and physical education humanities

\section{REFERENCES}

[1] Liangfang Shi. Curriculum Theory -- Fundamentals, Principles and Problems of Curriculum [M]. Beijing: Educational Science Publishing House, 1996:21.

[2] Jinghan Wang. The Construction and Discussion of the Teaching Model of Physical Education Curriculum in Colleges and Universities [J]. Contemporary Sports Technology, 2017,7(5):6.

[3] Wenwu Hu, Liaokun Ye. Feasibility Analysis on the Implementation of "Modular" Teaching Model in Public Physical Education Courses in Colleges and Universities [J]. Contemporary Sports Technology,2017, 7(11):71.

[4] Huaizhi Lu. Retrospect and Reflection on the Evolution of School Physical Education in New China $[\mathrm{J}]$. Journal of Liaoning Teachers College, 2004:6(2):50.

[5] Chunmei Zhang, Huiling Li. On the Development Trend of Teaching Materials and Teaching Methods of Physical Education in the 21st Century [J]. Liaoning Sport Science and Technology, 1999: (2):47-48. 